\title{
Changes in Inflammatory Biomarkers Related to C- reactive Protein and Albumin in Patients With Terminal Cancer Receiving Palliative Care: a Longitudinal Study
}

\section{EMANUELLY VAREA MARIA WIEGERT ( $\sim$ manuvarea@gmail.com )}

NATIONAL CANCER INSTITUTE JOSÉ ALENCAR GOMES DA SILVA (INCA) https://orcid.org/0000-00015904-5287

\section{LARISSA CALIXTO-LIMA \\ National Cancer Institute}

GABRIELLA DA COSTA CUNHA

National Cancer Institute

Tais Saint Martin Fonseca

National Cancer Institute

GEISIANE ALVES DA SILVA

National Cancer Institute

LIVIA COSTA DE OLIVEIRA

National Cancer Institute

\section{Research Article}

Keywords: CRP, albumin, biomarkers, inflammation, terminal cancer, palliative care

Posted Date: September 2nd, 2021

DOl: https://doi.org/10.21203/rs.3.rs-657121/v1

License: (a) (i) This work is licensed under a Creative Commons Attribution 4.0 International License. Read Full License 


\section{Abstract}

Background: Evidence about how inflammatory biomarkers vary during the end-stage cancer trajectory is lacking. This study investigates the longitudinal changes in albumin and C-reactive protein (CRP) levels, and CRP/albumin ratio (CAR) in patients with terminal cancer receiving palliative care in the last three months of life.

Methods: This is a retrospective analysis of variables extracted from a prospective cohort study that included admitted patients to the exclusive Palliative Care Unit of the National Cancer Institute in Brazil. Routine blood examination results of albumin and CRP were recorded at 0-15 (T1), 16-30 (T2), 31-45 (T3), 46-60 (T4), 61-75 (T5), and 76-90 (T6) days before death and only patients with at least two measurements were included. Crude and adjusted linear mixed-effects regression models were performed to verify the relationships between the longitudinal trajectories of biomarkers and death.

Results: A total of 1,635 patients were included. Median albumin was $3.00 \mathrm{~g} / \mathrm{dL}$ across the whole timeperiod analyzed (interquartile range, IQR: 2.50-3.60) and decreased with the approach of death, while median CRP was $9.31 \mathrm{mg} / \mathrm{L}$ (IQR: 4.42-17.30) and CAR was 3.20 (IQR: 1.40-6.60), and both increased. The albumin (slope: 0.01 to $0.02 ; p<0.001$ ), CRP (slope: -0.10 to $-0.12 ; p<0.001$ ), and CAR (slope: $-0.06 ; p$ $<0.001$ ) showed a linear dose-response relationship with death in crude and adjusted models tested.

Conclusions: The longitudinal change levels of inflammatory biomarkers worsen with the approach of death and could be used to predict end-stage in patients with terminal cancer.

\section{Introduction}

In the terminal phase of cancer, accurate prognostication is important in aiding clinical decision-making, for example, about systemic therapies, palliative procedures, or artificial nutrition or hydration, and in planning and preparing for the time ahead [1]. There are significant barriers to consistently and accurately identifying the end-of-life phase and no definitive diagnostic criteria exist [2]. Although several prognostic tools have been validated, they vary in their complexity, subjectivity, and therefore their clinical utility [3]. It would therefore be useful to rationalize these subjective assessments into a simpler format by carefully selecting and refining existing tools. Biological factors have the potential to be used in such cases, helping to overcome the limited understanding of the process of dying [4].

There are many biological prognostic factors that are associated with the terminal disease process, but some of them may have limited applicability. Cancer-associated inflammation leads to poor survival which means biomarkers of systemic inflammation are objective criteria with the potential to assist clinicians in recognizing dying [5]. A systematic review reporting prognostic biomarkers in patients with cancer in the last months of life described seven prognostic factors with a high level of evidence, namely, lymphocyte count, white blood cell count, serum C-reactive protein (CRP), albumin, sodium, urea, and alkaline phosphatase [4]. 
There is ample literature on hypoalbuminemia and elevated CRP as a prognostic biomarker in patients with cancer [5]. In addition, indices based on albumin and CRP levels, such as the Glasgow Prognostic Score (GPS) $[5,6]$ or the CRP/albumin ratio (CAR) $[5,7]$ have shown good prognostic predictability for several types of incurable cancer. This rationale indicates that significantly deranged albumin and CRP values could signal a relatively short remaining survival time in patients with incurable cancer $[8,9]$.

Currently evidence about how inflammatory markers varies during the disease trajectory is lacking, as most studies available in the literature are cross-sectional, and generally assess biomarkers as a single threshold value at baseline, consequently revealing little about the long-term linear changes of these biomarkers as the disease progresses. In that regard, studies that assess longitudinal inflammatory biomarker levels and their changes over time in relation to well-defined events such as death may help improve prognostic information and plan supportive care.

Our main hypothesis is that albumin and CRP are inflammatory biomarkers that worsen progressively with the approach of death and may express terminal cancer phase. To the best of our knowledge, to date no longitudinal studies have explored changes in these biomarkers' levels during the last months of life of patients with cancer. Thus, in this study, we investigated the longitudinal changes in albumin and Creactive protein (CRP) levels, and CRP/albumin ratio (CAR) in patients with terminal cancer receiving palliative care in the last three months of life.

\section{Methods}

\section{Patients and data collection}

This was a secondary analysis of data from a prospective cohort study conducted in the Palliative Care Unit (PCU) at the José Alencar Gomes da Silva National Cancer Institute (INCA) in Brazil. The INCA research ethics committee (protocol number 1.407.458 of 2016) approved the study protocol, and each patient provided informed consent before participating in the research.

Patients included in the original cohort of the study were evaluated during their first attendance at the PCU by trained researchers between July 27, 2016 and March 18, 2020. The patients all had metastatic or locally advanced malignancy and were no longer subject to specific anticancer therapy with curative intent. The focus of care in the PCU is symptom-oriented. It commences when anti-tumor treatment is discontinued because of lack of effect and/or severe side-effects. The KPS score (ranging from 0 [death] to 100 [full function]) was assigned according to patient-reported daily physical function. ${ }^{10}$ The study population has been described in more detail elsewhere [11-14].

From 2,153 patients eligible in the original dataset, 49 patients were initially excluded because they were previously diagnosed with an infectious or autoimmune disease (human papillomavirus $n=1$, paracoccidioidomycosis $n=1$, tuberculosis $n=1$, psoriasis $n=1$, lupus $n=1$, vitiligo $n=1$, rheumatoid arthritis $n=4$, pneumopathy $n=15$, and human immunodeficiency virus infection $n=22$ ). Routine blood 
examination results of serum albumin and CRP levels were retrospectively collected from the patients' electronic records. CAR values were calculated using the same blood samples. The follow-up period was 90 days from the date of death. This time point was chosen because it generally coincides with the terminal cancer phase [15]. The time periods considered for analysis (in days) were: 0-15 (T1), 16-30 (T2), 31-45 (T3), 46-60 (T4), 61-75 (T5), and 76-90 (T6). When there was more than one measurement in the same time interval, the one closest to the date of death was used. Only patients with at least two study measurements (consecutive or not) were included in the longitudinal analysis. Thus, a total of 469 patients were excluded because they had only one or less data point for the CRP or albumin. A flow chart of the study is presented in Fig. 1.

\section{Covariate Assessment}

The covariates were recorded at baseline; that is, on the date of the patient's entry to the cohort, by trained researchers. The demographic data (age and sex) and clinical data (primary tumor site, tumor progression, previous antitumor treatment) were collected from the patients' electronic records. Weight $(\mathrm{kg})$ was measured using a calibrated portable scale (Wiso $\AA$ ) with an accuracy of $0.1 \mathrm{~kg}$. For patients unable to stand, the Stryker® GoBed II in-bed weight system was used (Stryker Medical, USA). Height (m) was measured using a tape stadiometer on the wall. When this could not be used, height was estimated using the Chumlea et al. formulas [16, 17]. Body mass index was calculated by dividing weight by height squared and expressed in $\mathrm{kg} / \mathrm{m}^{2}$. Muscle strength was assessed by handgrip strength (HGS, $\mathrm{kg}$ ) using a Jamar ${ }^{\circledR}$ hydraulic hand dynamometer (Baseline, Fabrication Enterprises Inc, Elmsord, USA). Three trials were performed per hand, with a 1-minute rest interval between the trials of each hand. Maximum strength was defined as the greatest of the six measurements and used to represent HGS. Low muscle strength was defined when the HGS value was lower than the 25th percentile [14]. All the patients completed the Portuguese validated version of the Patient-Generated Subjective Global Assessment (PGSGA, CFD Ottery, 2015), available in pt-goblal.org [18]. The short form version (PG-SGA SF) consists of the first four-part of the questionnaire based on patient-reported weight, food intake, symptoms, and physical function. The total score of the PG-SGA SF is the sum of the scores of these four parts and the higher this score, the greater the nutritional risk.

\section{Data analysis}

The statistical analyses were conducted using Stata ${ }^{\circledR} 13.1$. The Kolmogorov-Smirnov test was performed to assess the distribution of the variables. Median and interquartile range (IQR) were used to describe the continuous variables, and number of observations and frequencies were used for the categorical variables. The descriptive statistics for the laboratory characteristics included all the data points collected for each parameter. Significance was set at $5 \%$ for all the statistical tests.

Changes in the trajectory of biomarkers until death were assessed using longitudinal linear mixed-effects (LME) analysis. LME regression coefficients (slopes) provide a combined estimate of the effect between 
and within the participants $[19,20]$. The models were fitted using the unstructured covariance matrix. Time until death (in days) was included in all the LME models as both a random and a fixed effect to adjust for the overall and individual variations in the biomarker concentrations over time. All the other covariables were considered as fixed effects only. This analysis technique provided a random coefficient and an intercept. The coefficient provided a combined estimate of a "mean" trajectory for the patient cohort, describing the relationship between the variable value and time to death (note that a value that increases as death approaches will therefore have a negative coefficient). The intercept predicts the mean values of the biomarkers at time is zero (death). It acts as a useful "end point" for the predicted trajectory for clinical interpretation; i.e., if the intercept is within or near the normal range of clinical values, this suggests that the variable will have limited clinical significance in application, even where the model is statistically significant [21].

Serum albumin, CRP, and CAR were considered as time-dependent variables (variables that varied before death). Four models were designed to compare the best relationship between the main exposure variables (biomarkers) and the outcome (death). Model 1 included all patients with $\geq 2$ measures, without adjusting for variables (crude). Model 2 included all patients with $\geq 2$ measures, adjusted for significant factors according to the univariate analysis $(p<0.25)$ (adjusted). Model 3 included all patients with only 2 measures, without adjusting for variables (crude). Model 4 included all patients with $\geq 3$ measures, without adjustments (crude). Figures presenting the scatter plot and longitudinal linear prediction (using model 1) were constructed to illustrate the variation of serum albumin, CRP, and CAR in the last three months before patients' death.

\section{Results}

\section{Summary of baseline information}

A total of 1,635 patients were included in this analysis. There was no statistical difference between the sample analyzed and the excluded patients in relation to age $(p=0.425)$, sex $(p=0.415)$, primary tumor site $(p=0.512)$, and KPS ( $p=0.228)$ (data not shown). The median age was 63 years (IQR: $53-71$ years), and $58.7 \%$ were female. The most common primary cancer sites were gastrointestinal tract $(30.0 \%)$ and gynecological (18.4\%). KPS 50\%-60\% and distant metastatic disease were observed in $47.2 \%$ and $74.1 \%$ patients, respectively (Table 1 ). 
Table 1

Baseline demographic and clinical characteristics of the patients included in this study $(n=1,635)$.

\section{Sex}

Variables

Age (years) $^{a}$

Female

Primary tumor site

GI tract ${ }^{b}$

Gynecologicalc $^{\mathrm{C}}$

Breast

Head and neck ${ }^{d}$

Lung

Skin

Bones and soft tissues

Kidney and urinary tract

Others $^{\mathrm{e}}$

\section{Tumor progression}

Locally recurrent

Distant metastases

\section{Current medical status}

Inpatient

Outpatient

\section{Previous antitumor treatment}

Chemotherapy

Radiotherapy

Surgery

KPS (\%)

$\geq 70$

$50-60$ $\mathrm{n}(\%)$

$63(53 ; 71)$

$960(58.7)$

$490(30.0)$

301 (18.4)

$200(12.2)$

$200(12.2)$

$166(10.1)$

$73(4.5)$

55 (3.4)

$41(2.5)$

109 (6.7)

423 (25.9)

$1212(74.1)$

$392(24.0)$

$1243(76.0)$

1106 (67.7)

$776(47.5)$

$669(40.9)$

226 (13.8)

772 (47.2) 


\section{Variables}

$30-40$ n (\%)

$637(39.0)$

Note: $\mathrm{n}=$ number of observations; $\%$ = frequency; GI= Gastrointestinal; KPS= Karnofsky Performance Status.

${ }^{a}$ Median (interquartile range).

bUpper and lower GI tract.

${ }^{c}$ Cervix, uterus, endometrium, ovary and vulva.

dOral and nasal cavity, pharynx, larynx, salivary glands, paranasal sinuses, thyroid and eyes.

e'Central nervous system, hematologic, male genital organs, peritoneum, mediastinum and unrecognized site.

Descriptive statistics including all the data points collected are summarized in Table 2. Median albumin was $3.00 \mathrm{~g} / \mathrm{dL}$ across the whole time-period analyzed (IQR: 2.50-3.60) and decreased with the approach of death (3.40 to $2.60 \mathrm{~g} / \mathrm{dL}$ ). In contrast, median CRP was $9.31 \mathrm{mg} / \mathrm{L}$ (IQR: $4.42-17.30$ ) and median CAR was 3.20 (IQR: $1.40-6.60$ ), and both increased before death (CRP: 5.83 to $14.17 \mathrm{mg} / \mathrm{L}$ and CAR: 1.60 to $5.90 \mathrm{mg} / \mathrm{L})$. 
Table 2

Descriptive statistics for all data collected of the patients with terminal cancer.

\begin{tabular}{|c|c|c|c|c|c|c|c|}
\hline & $\begin{array}{l}\text { Time to } \\
\text { death }\end{array}$ & $\begin{array}{l}\text { Number of } \\
\text { observations/ Patients }\end{array}$ & $\begin{array}{l}\text { 5th } \\
\text { centile }\end{array}$ & $\begin{array}{l}\text { 25th } \\
\text { centile }\end{array}$ & $\begin{array}{l}\text { 50th } \\
\text { centile }\end{array}$ & $\begin{array}{l}\text { 75th } \\
\text { centile }\end{array}$ & $\begin{array}{l}\text { 95th } \\
\text { centile }\end{array}$ \\
\hline \multirow{7}{*}{$\begin{array}{l}\text { CRP } \\
(\mathrm{mg} / \mathrm{L})\end{array}$} & & $2706 / 961$ & 0.78 & 4.42 & 9.31 & 17.30 & 32.56 \\
\hline & $\mathrm{T} 1$ & 737 & 1.82 & 7.15 & 14.17 & 24.31 & 36.90 \\
\hline & $\mathrm{T} 2$ & 540 & 1.01 & 4.88 & 9.43 & 17.33 & 32.30 \\
\hline & T3 & 446 & 0.75 & 3.76 & 7.62 & 14.00 & 26.65 \\
\hline & $\mathrm{T} 4$ & 391 & 0.58 & 3.90 & 7.64 & 14.28 & 27.00 \\
\hline & T5 & 323 & 0.47 & 3.25 & 8.13 & 14.40 & 25.80 \\
\hline & T6 & 269 & 0.43 & 2.54 & 5.83 & 11.10 & 28.10 \\
\hline \multirow{7}{*}{$\begin{array}{l}\text { Alb } \\
(\mathrm{g} / \mathrm{dL})\end{array}$} & & $4517 / 1635$ & 1.90 & 2.50 & 3.00 & 3.60 & 4.20 \\
\hline & $\mathrm{T} 1$ & 1315 & 1.60 & 2.20 & 2.60 & 3.10 & 3.80 \\
\hline & $\mathrm{T} 2$ & 858 & 1.90 & 2.50 & 3.00 & 3.50 & 4.10 \\
\hline & T3 & 735 & 1.90 & 2.60 & 3.10 & 3.60 & 4.20 \\
\hline & $\mathrm{T} 4$ & 625 & 2.20 & 2.80 & 3.30 & 3.70 & 4.40 \\
\hline & T5 & 528 & 2.30 & 3.00 & 3.40 & 3.80 & 4.30 \\
\hline & $\mathrm{T} 6$ & 456 & 2.30 & 3.00 & 3.40 & 3.90 & 4.50 \\
\hline \multirow[t]{7}{*}{ CAR } & & $2007 / 833$ & 0.23 & 1.40 & 3.20 & 6.60 & 14.30 \\
\hline & $\mathrm{T} 1$ & 593 & 0.59 & 2.90 & 5.90 & 10.30 & 18.00 \\
\hline & $\mathrm{T} 2$ & 410 & 0.33 & 1.60 & 3.10 & 6.50 & 13.60 \\
\hline & T3 & 320 & 0.22 & 1.05 & 2.55 & 4.90 & 11.55 \\
\hline & $\mathrm{T} 4$ & 263 & 0.18 & 1.10 & 2.40 & 4.90 & 10.70 \\
\hline & $\mathrm{T} 5$ & 228 & 0.12 & 0.83 & 2.30 & 5.20 & 11.10 \\
\hline & T6 & 193 & 0.11 & 0.68 & 1.60 & 3.30 & 9.65 \\
\hline \multicolumn{8}{|c|}{$\begin{array}{l}\text { Note: } \mathrm{CRP}=\mathrm{C} \text {-reactive protein; } \mathrm{Alb}=\text { albumin; } \mathrm{CAR}=\mathrm{CRP} / \text { albumin ratio. } \\
\text { aTime before death (in days): } \mathrm{T} 1=0-15 ; \mathrm{T} 2=16-30 ; \mathrm{T} 3=31-45 ; \mathrm{T} 4=46-60 ; \mathrm{T} 5=61-75 \text {; and } \mathrm{T} 6=76 \text { - } \\
\text { 90. }\end{array}$} \\
\hline
\end{tabular}




\section{Association of change in inflammatory biomarkers with death}

A significant negative correlation between CRP and albumin levels was observed; CRP and CAR increased, while albumin levels showed significant reduction during the last 90 days of life (Fig. 2). The LME analysis revealed that serum albumin $(p<0.001)$, CRP $(p<0.001)$, and CAR $(p<0.001)$ showed a significant linear dose-response relationship with time to death (slope significantly different from 0 ). In other words, the results of the longitudinal analysis showed a significant increase in CRP (slope: -0.10 to -0.12 ) and CAR (slope: -0.06 ) and a decrease in albumin (slope: 0.01 to 0.02 Table 3). 
Table 3

Longitudinal mixed effects models for inflammatory biomarkers in the last three months before death in patients with terminal cancer.

\begin{tabular}{|c|c|c|c|c|c|}
\hline Variables & Models & $\begin{array}{l}\text { Number of observations/ } \\
\text { patients }\end{array}$ & $\begin{array}{l}\text { Intercept } \\
(95 \% \mathrm{Cl})\end{array}$ & $\begin{array}{l}\text { Slope }^{\mathrm{a}} \\
(95 \% \mathrm{Cl})\end{array}$ & $\begin{array}{l}P \\
\text { value }^{\mathrm{b}}\end{array}$ \\
\hline \multirow[t]{4}{*}{$\begin{array}{l}\text { CRP } \\
(\mathrm{mg} / \mathrm{L})\end{array}$} & 1 & 2706 / 961 & $\begin{array}{l}45.00(41.20 \\
48.80)\end{array}$ & $\begin{array}{l}-0.11(-0.12 \\
-0.10)\end{array}$ & $\hat{0.001}$ \\
\hline & 2 & 2704 / 960 & $\begin{array}{l}44.80(41.20 \\
48.80)\end{array}$ & $\begin{array}{l}-0.11(-0.12 \\
-0.10)\end{array}$ & $\dot{0} 001$ \\
\hline & 3 & $1258 / 629$ & $\begin{array}{l}46.60(41.70 \\
52.00)\end{array}$ & $\begin{array}{l}-0.12(-0.14 \\
-0.11)\end{array}$ & $\hat{0} .001$ \\
\hline & 4 & $1448 / 423$ & $\begin{array}{l}44.30(39.80 \\
49.30)\end{array}$ & $\begin{array}{l}-0.10(-0.12 \\
-0.08)\end{array}$ & <. 001 \\
\hline \multirow[t]{4}{*}{$\begin{array}{l}\text { Alb } \\
(g / d L)\end{array}$} & 1 & 4517 / 1635 & $0.16(0.15 ; 0.17)$ & $\begin{array}{l}0.01(0.01 \\
0.01)\end{array}$ & $\hat{0} 001$ \\
\hline & 2 & $4210 / 1519$ & $0.16(0.15 ; 0.18)$ & $\begin{array}{l}0.01(0.01 ; \\
0.01)\end{array}$ & $<.001$ \\
\hline & 3 & $1572 / 786$ & $0.19(0.16 ; 0.21)$ & $\begin{array}{l}0.02(0.01 \\
0.01)\end{array}$ & $\dot{0} 001$ \\
\hline & 4 & 2944 / 850 & $0.15(0.14 ; 0.16)$ & $\begin{array}{l}0.01(0.01 \\
0.01)\end{array}$ & $<.001$ \\
\hline \multirow[t]{4}{*}{ CAR } & 1 & 2007 / 833 & $8.49(7.67 ; 9.39)$ & $\begin{array}{l}-0.06(-0.06 \\
-0.05)\end{array}$ & <. 001 \\
\hline & 2 & $1868 / 775$ & $7.78(7.01 ; 8.63)$ & $\begin{array}{l}-0.06(-0.07 \\
-0.05)\end{array}$ & $<.001$ \\
\hline & 3 & 1159 / 581 & $7.91(7.05 ; 8.87)$ & $\begin{array}{l}-0.06(-0.07 \\
-0.05)\end{array}$ & $<.001$ \\
\hline & 4 & 848 / 254 & $\begin{array}{l}9.00(7.80 \\
10.39)\end{array}$ & $\begin{array}{l}-0.06(-0.07 \\
-0.05)\end{array}$ & $\hat{0.001}$ \\
\hline
\end{tabular}




\begin{tabular}{|lllll|}
\hline Variables & Models & $\begin{array}{l}\text { Number of observations/ } \\
\text { patients }\end{array}$ & $\begin{array}{l}\text { Intercept } \\
(95 \% \mathrm{Cl})\end{array}$ & $\begin{array}{l}\text { Slope }^{\mathrm{a}} \\
(95 \% \mathrm{Cl})\end{array}$
\end{tabular}

Note: $\mathrm{Cl}=$ confidence interval; $\mathrm{CRP}=\mathrm{C}$-reactive protein; $\mathrm{Alb}=$ albumin; $\mathrm{CAR}=\mathrm{CRP} /$ albumin ratio.

aslope is a model predicted change in value per day prior to death.

${ }^{\mathrm{b}} P$ value refers to longitudinal linear mixed-effects.

Model 1: Included $\geq 2$ data points without adjust for confounder variables.

Model 2: Included $\geq 2$ data points with adjust for confounder variables*.

Model 3: Included only 2 data points without adjust for confounder variables.

*The variables with $P<0.25$ in univariate analysis: age (years), sex (female), Karnofsky Performance Status (\%), primary tumor site (gastrointestinal tract/others), distant metastasis (yes/no), systemic treatment (yes/no), body mass index $\left(\mathrm{kg} / \mathrm{m}^{2}\right)$, weight loss in 6 months $(\%)$, handgrip strength $\left(<25^{\text {th }}\right.$ percentile), and score of Patient-Generated Subjective Global Assessment (points).

\section{Discussion}

In this study, we evaluated inflammatory biomarkers at baseline and within three months until death of patients who received palliative care for terminal cancer. Our findings provide novel evidence that there was a significant longitudinal linear relationship between change in CRP, CAR and albumin and death. CRP and CAR levels increased while albumin decreased during the last three months of life.

Systemic inflammation is a recognized as a hallmark of cancer and reflects the body's defense to mitotic processes and develops through the action of various proinflammatory mediators, including cytokines, such as interleukins (IL) 1, IL 6 and tumor necrosis factor alpha (TNF-a) leading to accelerated tumor progression [22-24]. According to our results, terminal cancer is related to a progressive increase in serum CRP/CAR levels, and a decrease in serum albumin levels with the approach of death. This can be explained by the fact that cytokines play a role in inflammation, including induction of acute phase reactants and down-regulation of albumin production, therefore CRP synthesis by the liver increases as the disease progresses, while albumin synthesis could be significantly decreased [25].

The current findings are of clinical importance given that these biomarkers are commonly available as part of the standard routine management of patients with cancer. In addition, assessing the change in a variable rather than an absolute value at a single point in time is crucial because albumin and CRP alterations over time indicate an ongoing increase in inflammation. Furthermore, there is lesser susceptibility to biases related to an acute elevation of the biomarker.

Another point to be mentioned is that prognostic scoring systems $[3,6,26,27]$ are typically developed from cross sectional data in relation to survival, and this technique allows a measure of association between a variable cut-off value and time but assumes a common trajectory among individuals [21]. Our 
findings demonstrated that the assessment of the rate of change over time of the biomarkers (trajectory) demonstrated prognostic predictive power. These suggest that CRP, albumin and CAR could be used to predict death in patients with incurable cancer referred for exclusive palliative care regardless of a specific cut-off point evaluated by a single measurement at baseline.

The median concentrations of inflammatory biomarkers in our study were worse than those reported in a longitudinal study in patients with acute myeloid leukaemia [28] which may be explained by the fact that our study dealt with patients at the most advanced stage of the disease. To our knowledge, no studies have specifically studied longitudinal albumin, CRP, and CAR in an exclusive palliative setting. Concerning cross-sectional studies that involve patients with cancer in palliative care $[4,8,9,29]$ median and cut-off values vary according to the cancer population and period analyzed which makes it difficult to compare our results with those observed in other previous studies.

At the present time there is no consensus on the best cutoff points for CRP, albumin and CAR, with different studies using different values as reference [5, 7]. The meta-analysis conducted by Dolan et al. [5] showed variation in the cutoff points for albumin and CRP in the included studies. The most widely used cut-off point in the 63 articles that assessed the prognostic power of CRP was $>10 \mathrm{mg} / \mathrm{L}(\mathrm{n}=19 ; 30.1 \%)$, followed by $>5 \mathrm{mg} / \mathrm{L}(\mathrm{n}=5 ; 7.9 \%)$. As for the 33 that related albumin to overall survival, the most common cutoff points studied were $<3.5 \mathrm{~g} / \mathrm{dL}(\mathrm{n}=13 ; 39.4 \%)$ and $<3.0 \mathrm{~g} / \mathrm{dL}(\mathrm{n}=5 ; 15.1 \%)$. According to the results of a meta-analysis by Li et al. [7] different CAR cutoff points, ranging from 0.25 to 6.7 , are used to describe the association between CAR and overall survival [29].

Regarding the intercept values, our results provided a combined estimate of the associations between participants and within participants over time as a useful "end point" indication of predicted or expected values for that variable as death approaches. The clinical interpretation consists in observing that these values were above the normal reference limits or thresholds values of these biomarkers [21]. In addition, it is worth highlighting that according to our crude and adjusted LME models, changes in inflammatory biomarkers over 90 days were associated with death regardless of age, sex, KPS, primary tumor site, distant metastasis, previous systemic treatment, BMI, percentage weight loss in six months, HGS, and score of PG-SGA SF. In practical terms, for example each $0.11 \mathrm{mg} / \mathrm{L}$ increase in CRP above the mean CRP at baseline was associated with one-day survival reduction, or considering the mean baseline value is expected a 0.9 to $1.8 \mathrm{~g} / \mathrm{dL}$ decrease in serum albumin levels and an increase of 9.0 to $10.8 \mathrm{mg} / \mathrm{L}$ in CRP and 5.4 CAR levels until patient's death. Another important point was that the inclusion of more than two measures in the multivariate model did not alter our results. It is interesting to note that two routine measurements of blood-based biomarkers were enough to observe such dynamics in relation to death.

Although the current study presents clinically relevant data, there are strengths and weaknesses that should be considered when interpreting our findings. The strength is the longitudinal design of the study, which allowed a better understanding of the relationship between the biomarkers evaluated and the patients' prognosis. A potential weakness was the high number of excluded patients. However, no differences were observed in relation to demographic and clinical variables when we compared the 
excluded and the analyzed patients. To the best of our knowledge, this is the only study that has described changes in albumin, CRP, and CAR values in patients with terminal cancer receiving exclusive palliative care using an LME model. Thus, comparisons between our data and the available literature are limited. Finally, this was a single-center study without an external validation cohort, which limits generalizability of the study results.

Identification of biomarkers of dying is an important area for future research, which could contribute to improved clinical practices for patient management. However, further investigations in multicenter studies are required to understand how these laboratory measures and proposed cutoffs should be used to better employ biomarkers in prognostication of terminal cancer.

\section{Conclusion}

This study of longitudinal measures allowed the exploration of the inflammatory biomarker's response throughout the end-of-life and demonstrated that decreased albumin levels and increased CRP and CAR values are significantly related to the terminal illness process in the last three months of life of patients with cancer. Appraisal of these biomarkers may be useful in clinical practice to predict survival in patients with cancer in palliative care.

\section{Declarations}

\section{Financial disclosure}

This research received no specific grant from any funding agency in the commercial or not-for-profit sectors.

\section{Conflicts of interest}

None declared. On behalf of all authors, the corresponding author states that there is no conflict of interest.

\section{Availability of data and material}

$\mathrm{N} / \mathrm{A}$

Code availability

N/A

\section{Authors' contributions}

E. V. M. Wiegert, L. Calixto-Lima, G. C. Cunha, T. S. M. Fonseca, G. A. da Silva, L. C. Oliveira, contributed to the conception and design of the research; E. V. M. Wiegert, L. Calixto-Lima G. C. Cunha, T. S. M. Fonseca, G. A. da Silva, L. C. Oliveira, contributed to the acquisition and analysis of the data; E. V. M. Wiegert, L. 
Calixto-Lima, G. C. Cunha, T. S. M. Fonseca, G. A. da Silva, L. C. Oliveira, contributed to the interpretation of the data; and E. V. M. Wiegert, L. Calixto-Lima, L. C. Oliveira, drafted the manuscript. All authors critically revised the manuscript, agreed to be fully accountable for ensuring the integrity and accuracy of the work, and read and approved the final manuscript.

\section{Ethics approval}

This study was performed in line with the principles of the Declaration of Helsinki. Approval was granted by the Ethics Committee of INCA (protocol number 1.407.458 of 2016).

\section{Consent to participate}

Each patient provided informed consent before participating in the research.

\section{Consent for publication}

$N / A$

\section{References}

1. Hui D, Paiva CE, Del Fabbro EG, et al. (2019) Prognostication in advanced cancer: update and directions for future research. Support Care Cancer 27:1973-1984.

2. Hui D, Nooruddin Z, Didwaniya N, et al. (2014) Concepts and definitions for "actively dying," "end of life," "terminally ill," "terminal care," and "transition of care": a systematic review. J Pain Symptom Manage 47:77-89.

3. Simmons CPL, McMillan DC, McWilliams K, et al. (2017) Prognostic tools in patients with advanced cancer: a systematic review. J Pain Symptom Manage 53:962-970.e10.

4. Reid VL, McDonald R, Nwosu AC, et al. (2017) A systematically structured review of biomarkers of dying in cancer patients in the last months of life; An exploration of the biology of dying. PLOS ONE 12:e0175123.

5. Dolan RD, McSorley ST, Horgan PG, Laird B, McMillan DC (2017). The role of the systemic inflammatory response in predicting outcomes in patients with advanced inoperable cancer: systematic review and meta-analysis. Crit Rev Oncol Hematol 116:134-146.

6. McMillan DC(2013) The systemic inflammation-based Glasgow Prognostic Score: a decade of experience in patients with cancer. Cancer Treat Rev 39:534-540.

7. Li N, Tian GW, Wang Y, Zhang H, Wang ZH, Li G(2017) Prognostic role of the pretreatment C-reactive protein/albumin ratio in solid cancers: a meta-analysis. Sci Rep 41298.

8. Gray S, Axelsson B (2018) The prevalence of deranged C-reactive protein and albumin in patients with incurable cancer approaching death. PLOS ONE 13:e0193693.

9. Ju SY, Ma SJ(2020) High C-reactive protein to albumin ratio and the short-term survival prognosis within 30 days in terminal cancer patients receiving palliative care in a hospital setting: a 
retrospective analysis. Medicine 99:e19350.

10. Schag CC, Heinrich RL, Ganz PA (1984) Karnofsky Performance Status revisited: reliability, validity, and guidelines. JCO 2:187-193.

11. Wiegert EVM, de Oliveira LC, Calixto-Lima L, Mota e Silva Lopes MSD, Peres WAF (2020) Cancer cachexia: Comparing diagnostic criteria in patients with incurable cancer. Nutrition 79-80:110945.

12. Silva GAD, Wiegert EVM, Calixto-Lima L, Oliveira LC (2020) Clinical utility of the modified Glasgow Prognostic Score to classify cachexia in patients with advanced cancer in palliative care. Clin Nutr 39(5):1587-92.

13. de Oliveira LC, Abreu GT, Lima LC, Aredes MA, Wiegert EVM (2020) Quality of life and its relation with nutritional status in patients with incurable cancer in palliative care. Support Care Cancer 10.1007/s00520-020-05339-7.

14. Wiegert EVM, da Silva NF, de Oliveira LC, Calixto-Lima L (2021) Reference values for handgrip strength and their association with survival in patients with incurable cancer. Eur J Clin Nutr doi:10.1038/s41430-021-00921-6.

15. Trajkovic-Vidakovic M, Graeff A, Voest EE, et al (2021) Symptoms tell it all: a systematic review of the value of symptom assessment to predict survival in advanced cancer patients. Crit Rev Oncol Hematol Oct;84(1):130-48.

16. Chumlea WMC, Guo SS, Steinbaugh ML (1994) Prediction of stature from knee height for black and white adults and children with application to mobility-impaired or handicapped persons. J Am Diet Assoc 94:1385-1391.

17. Chumlea WC, Guo S, Roche AF, Steinbaugh ML (1988) Prediction of body weight for the nonambulatory elderly from anthropometry. J Am Diet Assoc 88:564-568.

18. Ottery FD. Scored Patient-Generated Subjective Global Assessment (PG-SGA). Accessed April 30, 2016. http://pt-global.org.

19. Pinheiro JC. Mixed-Effects Models in S and S-PLUS. New York: Springer, 2000. Accessed September 8, 2020. http://link.springer.com/10.1007/b98882

20. Singer JD, Willett JB. Applied longitudinal data analysis: modeling change and event occurrence. New York: Oxford University Press; 2003. 672 p.

21. Taylor P, Crouch S, Howell DA, Dowding DW, Johnson MJ (2015) Change in physiological variables in the last 2 weeks of life: an observational study of hospital in-patients with cancer. Palliat Med 29:120-127.

22. Shalapour S, Karin M (2015) Immunity, inflammation, and cancer: an eternal fight between good and evil. J Clin Invest 125:3347-3355.

23. Munn LL (2017) Cancer and inflammation. Wiley Interdiscip Rev Syst Biol Med 9:e1370.

24. Negus RPM, Balkwill FR (1966). Cytokines in tumour growth, migration and metastasis. World J Urol 14:157-165. 
25. Dunlop RJ, Campbell CW (2000). Cytokines and advanced cancer. J Pain Symptom Manage 20:214232.

26. Baba M, Maeda I, Morita T, et al (2015) Independent validation of the modified Prognosis Palliative Care Study predictor models in three palliative care settings. J Pain Symptom Manage 49:853-860.

27. Gwilliam B, Keeley V, Todd C, et al (2011). Development of Prognosis in Palliative care Study (PiPS) predictor models to improve prognostication in advanced cancer: prospective cohort study. BMJ 343:d4920.

28. Gradel KO, Póvoa P, Garvik OS, et al (2020) Longitudinal trajectory patterns of plasma albumin and Creactive protein levels around diagnosis, relapse, bacteraemia, and death of acute myeloid leukaemia patients. BMC Cancer 20:249.

29. Cunha GDC, Rosa KSDC, Wiegert EVM, de Oliveira LC (2021). Clinical relevance and prognostic value of inflammatory biomarkers: a prospective study in terminal cancer patients receiving palliative care. J Pain Symptom Manage. doi:10.1016/j.jpainsymman.2021.04.009.

\section{Figures}

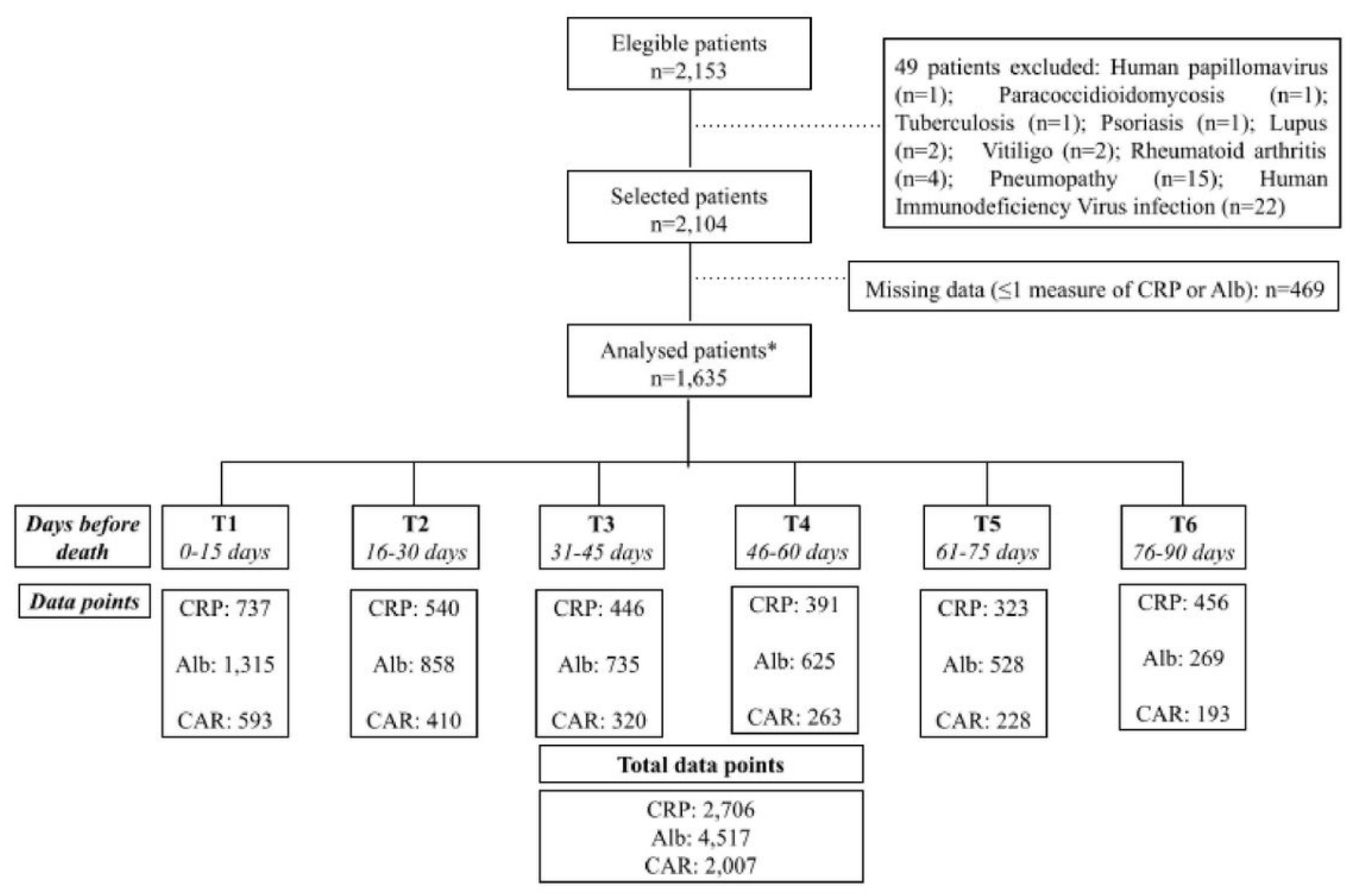


Figure 1

Flow chart of the participant selection process. Note: $n=$ number of observations; $C R P=C$-reactive protein; Alb= albumin; $C A R=C R P / a l b u m i n$ ratio. ${ }^{*}$ There was no statistical difference in the sample studied when compared to the all excluded (eligible and selected) patients in relation to age $(p=0.425)$, sex $(p=0.415)$, primary tumor site $(p=0.512)$ and Karnofsky Performance Status $(p=0.228)$.
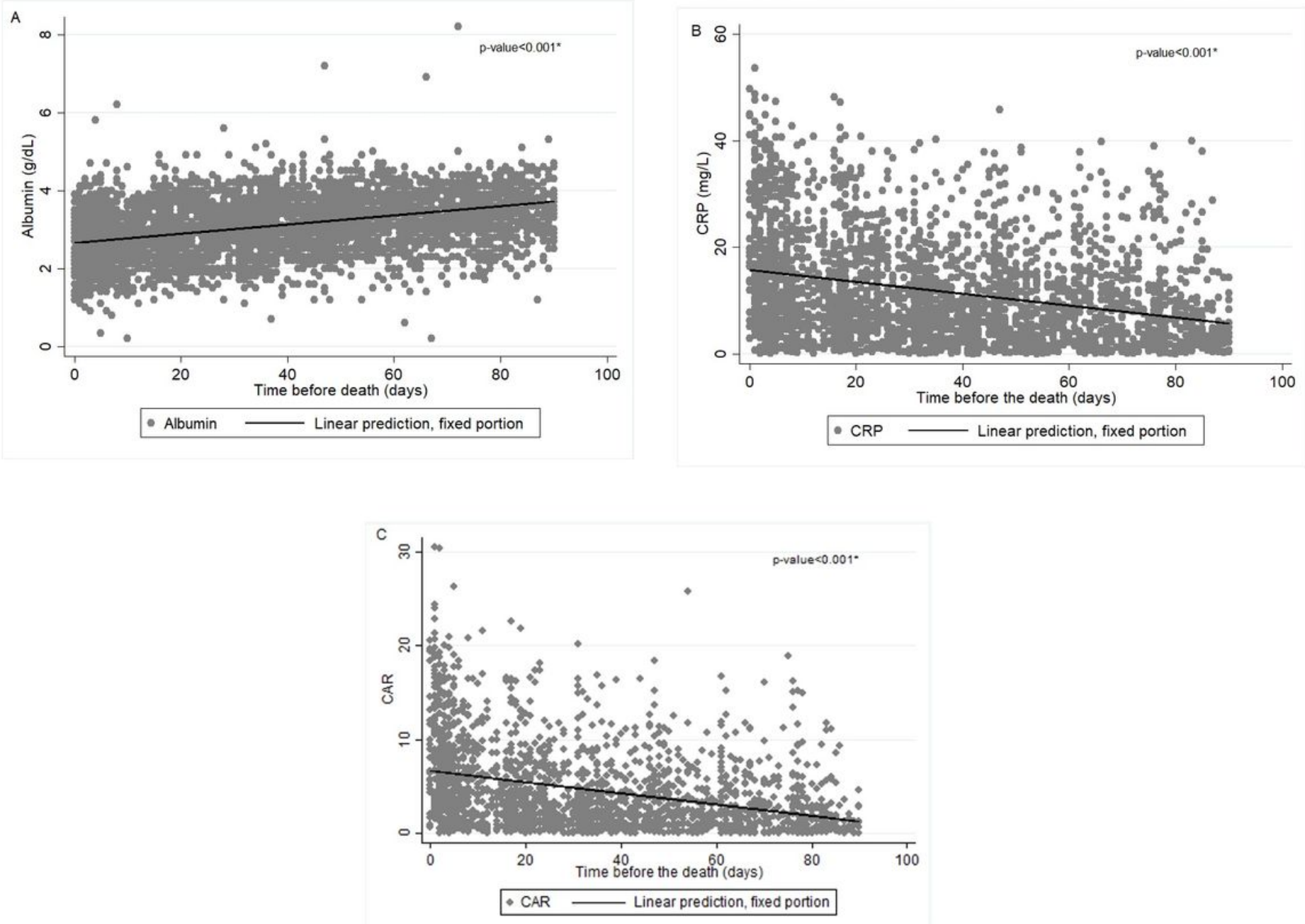

Figure 2

Changes in (A) albumin, (B) C-reactive protein and (C) C-reactive protein/albumin ratio until the days before death according to longitudinal linear mixed-effects analysis in patients with terminal cancer. Note: $\mathrm{CRP}=\mathrm{C}$-reactive protein; $\mathrm{CAR}=\mathrm{CRP} /$ albumin ratio. ${ }^{*} \mathrm{p}$ value refers to the statistical model including 